\title{
Reflections on Engineering Education in the Age of Globalization
}

\author{
Mohammad Ilyas, PhD \\ College of Engineering and Computer Science \\ Florida Atlantic University \\ Boca Raton, FL 33431 USA \\ ilyas@fau.edu
}

\begin{abstract}
Evolving phenomenon of globalization continues to impact all aspects of our lives. Education is no exception. All institutions of higher education must seriously consider including new educational dimensions created by the rapid emergence and impact of globalization. Of particular interest is engineering education in a globalized world. Educational institutions can and should play a major role in creating knowledge and awareness about all the aspects of globalization and in preparing their graduates and particularly engineering graduates with global competencies. In a globalized world, engineers are often required to work in multicultural teams, travel to different parts of the globe, and to execute the assigned tasks possibly in unfamiliar regions of the world. Global competencies promote having an open mind, actively seeking to understand cultural norms, and working effectively outside one's own comfort zone. This paper discusses various aspects that commit to engineering education with a focus on global competencies and producing graduates that are globally competent.
\end{abstract}

Keywords-Globalization, engineering education, global competencies.

\section{INTRODUCTION}

A quick look at the history of evolution of higher education reveals that two factors have played a significant role in this process. The first one is the phenomenon of globalization and the second one is rapidly emerging technologies [1.2]. In addition, globalization, and technologies, particularly information and communication technologies, are intricately related and fuel the growth of each other [3].

Globalization is a world-wide phenomenon and evolves with intended or unintended increase in interactions between groups, corporations, and nations. These interactions include economic, political, academic, and cultural aspects. These interactions push for greater international involvement in world affairs [4]. At the same time, rapid developments in information and communication technologies provide an ideal platform that facilitates these interactions.

As the process of globalization evolves, it enhances awareness of world affairs. Rapid exchange of information worldwide creates need and motivation for interactions among various entities. Among other aspects, these interactions between nations, particularly among developed and developing countries, promote competitiveness and motivation to push for

Digital Object Identifier (DOI):

http://dx.doi.org/10.18687/LEIRD2021.1.1.51

ISSN: 2414-6390 ISBN: 978-958-52071-9-6 a better education, better facilities, better opportunities, and better quality of life for everyone [5].

Higher education is a core component of societal needs in all developed and developing nations. Developing nations know that and relatively invisible forces of globalizations are pushing for better educational opportunities. Mass education era started in the middle of last century (since 1945) leading to better societal conditions. Contemporary education (since 1975) enhanced that trend, and the current educational era is continuing that exponential growth trajectory [6].

Engineering education has been and continues to be important in improving the quality of life of societies. It is even more important in the age of globalization. During the recent past, emerging technologies have increased the pace of globalization. Travel barriers are being softened, distances are shrinking, interaction among nations have increased, different cultures are permeating, and the world can be viewed as a global village [5]. Educating and preparing engineers for this globalized world has become essential because engineering workforce is often required to work in multicultural teams, travel to different parts of the globe, communicate ideas clearly, and have leadership and management skills to execute the assigned tasks, possibly in unfamiliar regions of the world. Engineers working in such environments must be equipped with global competencies to be effective and productive [7].

This paper focuses on the need and logistics of engineering education in the age of globalization. The paper includes discussion on skillset needed for being effective and productive in a globalized work environment. The paper particularly focuses on the need for including global competencies in engineering education. The next section discusses impact of globalization on higher education. Section III discusses globalization and engineering education. Section IV discusses integrations of global competencies in education particularly engineering education. Section V presents summary and conclusions of the paper.

\section{IMPACT OF GLOBALIZATION ON HIGHER EDUCATION}

American Council on Education [1] emphasizes that globalization process has created a need for changes in higher education. The report also emphasizes that the forces of globalization present both challenges and opportunities for the institutions of higher education. For successfully availing these 
opportunities and handling these challenges, it is necessary for the academic institutions to work with other institutions around the world [8]. The institutions have a responsibility to play a vital role in creating knowledge and awareness in preparing their graduates for a globalized workplace. This is even more necessary for engineering graduates $[9,10]$.

The phenomenon of globalization continues to impact today's learner in a very profound way. In examining the profile of today's learner, we can foresee the challenges they are expected to face during their studies and as they transition into the corporate world. An eight-minute YouTube video "Did you know" [11] and other similar narratives beautifully describe the future dynamics and changes that our planet is expected to experience in coming years/decades. It sets the stage for powerful technology trends, global competitiveness, and the challenges that next generations will need to prepare for. The following points present a summary of the relevant highlights of the video [11]:

- Twenty five percent of employees will stay with their employers for less than a year.

- Fifty percent of employees will stay with their employers for less than five years.

- Jobs and their nature will change very rapidly. It is a fact that top 10 jobs for 2010 did not even exist in 2004.

- Today's students/graduate is expected to have 10 to 14 different jobs by the age of 38 .

These startling statistics clearly indicate that today's students/graduates are very different than the ones only a few decades ago. Today's learners are much more comfortable with using technology much more effectively. They approach problem solving very differently, their reflexes and reactions are very different, their needs and motivations are very different, and they also plan their future very differently [12]. A few relevant projections/trends from the video include:

- Number of books published daily exceed 3000.

- The new information generated currently in one year is more than the total information generated in previous 5000 years.

- World population is expected to reach 10 billion by 2050.

- Worldwide information exchange is becoming almost instant.

- It is anticipated that by 2023 , computational capacity of a $\$ 1000$ laptop will exceed that of a human brain and by 2049 , it will exceed the computational capacity of human race.

Communication technologies have shrunk the distances. Most of the people are socializing online and many are making important decisions including marriages after meeting online. The processes for exchanging information and sharing the knowledge with rest of world are much easier and much faster. The world has essentially become a global village. People with diverse backgrounds are communicating with each other and embracing their differences. As we ponder what do these dynamics mean for academic institutions, one thing is certain that higher education must evolve and adapt to the new realities.

Higher education institutions must be prepared to produce graduates that have necessary skillset to successfully enter the workforce where knowledge is being produced mush faster and is also becoming outdated faster. If the knowledge continues to grow at an exponential rate, what will a university degree mean? If we do not adapt in the wake of new realities, we will not be educating the learners to solve problems of the future. Obviously, in coming years, learning is expected to become much more common and necessary not only for our students but also for employees to stay competitive in the job market and productive at their workplace $[13,14,15]$.

It is also expected that the corporate world of the future will also need to adapt to the new realities. There will be more effective design tools and technologies available to the employees. For corporations as well as their employees to stay competitive, the employers will need to allow generous time for employees' development. This will certainly lead to additional demand for learning. At the same time, the computational capabilities of computing machines will continue to increase and will lead to more automation. That will certainly disrupt the job market and nature of jobs available. Finding a balance between the use of human intelligence and artificial intelligence will be essential and an important decision. These dynamics may also lead to more and narrow specialties and learning will become highly selective. Furthermore, global collaborations as well as global competitiveness will increase [16,17].

Some academic institutions are already positioning themselves to serve the new learners effectively. Most of the institutions are embracing eLearning platforms to educate their students. Some universities have started offering complete degrees online and are expanding their reach beyond their borders. This has improved access to education for many. In addition, offering courses through MOOCs (Massive Open Online Courses) is changing the educational landscape by providing worldwide access to a variety of courses offered by experts in their fields [18].

\section{GLOBALIZATION AND ENGINEERING EDUCATION}

A brief review of history shows that societal needs, challenges, technological advancements, and context have always influenced engineering education. Whenever societal challenges emerge, higher learning institutions steer their research and educational efforts to find suitable and practical solutions. We all know when the world population growth rate was faster than the rate of food production, academic 
institutions found solutions that resulted in mechanization of agricultural processes. Implementation of these solutions breed new challenges and keep educational institutions moving forward. This cycle of progress continues, and the quality of life continues to improve. At the same time, educational institutions continue to adjust engineering education and curricula to prepare the engineering graduates well, to face the societal challenges and deliver effective and efficient solutions [13].

The phenomenon of globalization has essentially created a worldwide flat competitive environment where everyone has an opportunity to aim high and contribute based on his/her skills and ambitions. The globalization has also created an environment where people with different demographic, cultural, races, genders, and socio-economic status come together and work side-by-side. For individuals to be productive and effective, such a work environment requires additional skillsets including respect for different cultural traditions and norms. These additional skills are collectively referred to as global competencies [19,20]. These skills are even more crucial for engineers who often find themselves working in international teams with diverse backgrounds. Therefore, it is important for higher education institutions to carefully consider integrating global competencies in engineering education. Employers are increasingly assessing their future employees through the lens of global competencies along with their engineering skills.

There is no authentic definition of global competencies. However, many globalization experts agree that global competence imply "having an open-minded attitude and actively seeking to understand cultural norms and expectations of others" [21]. These competencies are essential for global citizens to be productive, engaged, and involved. These are even more essential for earlier generations who have witnessed the process of evolving globalization and its impact over several decades. At the same time, current generations also need to acquire global competencies because they are more likely to engage in a diverse workforce and work with individuals that look different, think different, and have different cultural values. Global competencies provide global citizens with global awareness and essential skillset to make individuals think differently and embrace the differences among fellow workers, communities, and nations. The mindset of globally competent citizens in general and globally competent engineers in particular, trigger a change in thinking and behavior that is necessary for success in a globalized world.

Characteristics of globally competent engineers include the following essential components, in addition to their technical skills:

- Appreciation for ethnic and geographical diversity.
- Sensitivity for diverse cultural norms, respect for diverse religious values, and respect for difference of opinions.

- Knowledge and awareness of world affairs.

- Knowledge and ability to evaluate international impact of engineering disciplines.

- Empathy and desire to find solutions for societal challenges that improve global conditions.

- Ability to effectively communicate in culturally diverse settings.

- Knowledge (written as well as verbal) of at least one more major language.

- Strong inclination to be a lifelong learner.

- Ability and desire to adapt to environment other than one's own zone of comfort.

There are several options for higher education institutions to integrate global competencies in engineering education. The next section discusses some of these options.

\section{INTEGRATION OF GLOBAL COMPETENCIES IN EDUCATION}

An undergraduate degree in engineering typically requires more credit hours than other degrees. These credit hours include intellectual foundation program (IFP) courses, core courses, and some technical elective courses. Curricula for engineering degrees are known for their rigidity and do not have sufficient flexibility. It is important for academic institutions to pursue innovative approaches to revise engineering curricula that, in addition to satisfying the degree requirements, integrates global competencies as well. Some of the available options to address these challenges, are listed here:

- Topics related to globalization, world cultures, and working environment in multinational corporations, can be added to IFP courses.

- Proficiency in another language can be added as a degree requirement (some institutions are already doing that).

- An internship requirement can be added for students to work in a multinational corporation.

- Existing courses (at least some of those) can be taught as study abroad courses where students are required to travel abroad, experience and interact with a globally diverse workforce, indulge in another culture, and acquire/practice global competency skills.

- Increase institutional diversity (including ethnic and geographical diversity) among students, faculty, and staff.

- Creating a welcoming environment for a diverse community that will lead to very positive interactions.

- Creating an office dedicated to educating cultural norms using avenues such as hosting multicultural functions, inviting diverse speakers, and embracing differences. 
- Providing commitment and support (from institutional leadership) to producing globally competent graduates.

- Encouraging faculty members, while teaching engineering courses, to choose examples, assignments, and problems that have international, diverse, and multicultural aspects.

Once there is a robust commitment, institutions of higher education can certainly exercise many other options [22] based on the availability of resources. As more and more institutions embrace the idea of educating their students and particularly engineering students with global competencies, they can certainly find ways to do it. Their graduates and employers will certainly be grateful for that.

\section{SUMMARY AND CONCLUSIONS}

With a rapid and continuous emergences of globalization phenomenon, and its impact on all aspects of world affairs, it is important for the institutions of higher education to play their role in educating and producing graduates that can be productive and effective in a globalized world. Educational institutions are intricately involved with what happens in the world and, therefore, they must play their role in addressing the challenges and opportunities created by the globalization phenomenon. Engineering education must be viewed as a critical part of the next generation of workforce. Therefore, it is essential to educate and produce globally competent engineers.

After a brief introduction to globalization, this paper discusses global competencies, and characteristics of globally competent engineers. The need for a robust commitment of educational institutions to integrate global competencies in the process of education, is emphasized. The paper then discusses various options/approaches to achieve integration of global competencies in the process of higher education, particularly in engineering education.

\section{REFERENCES}

[1] American Council on Education (ACE), Strength Through Global Leadership and Engagement: U.S. Higher Education in the $21^{\text {st }}$ Century, http://www.acenet.edu/news-room/documents/2011-cige-brpreport.pdf, Retrived in February 2021.

[2] Cohen, Arthur M. (1998). The shaping of American higher education. San Francisco: Jossey-Bass.

[3] Ilyas, M., "Globalization and Higher Education in Florida's State University System", Doctoral Dissertation, Florida Atlantic University, 2015.
[4] Altbach, P. G., and Knight, J., "The Internationalization of Higher Education: Motivations and Realities", Journal of Studies in International Education, 11(3/4), 2007, pp. 290-305.

[5] Friedman, T. L., "The World is Flat: A Brief History of the $21^{\text {st }}$ Century", New York, NY: Farrar, Straus, Giroux, 2005.

[6] Ilyas, M., "Evolution of Higher Education in USA and Role of Information and Communication Technologies", Proceedings of the $13^{\text {th }}$ International Multi-Conference on Society, Cybernetics, and Informatics (IMSCI 2019), Orlando, Florida, July 6-9, 2019, pp. $24-28$.

[7] Ilyas, M., "Curricular Aspects for Global Competencies in Engineering Education", Proceedings of the $18^{\text {th }}$ International Conference on Education and Information Systems, Technologies and Applications (EISTA 2020), Orlando, Florida, September 13-16, 2020.

[8] Duderstadt, J., "A University for the $21^{\text {st }}$ Century", Ann Arbor MI, University of Michigan Press, 2006.

[9] Brustein, W. I., "The Global Campus: Challenges and Opportunities for Higher Education in North America". Journal of Studies in International Education, 11(3/4), 2007, pp. 382-391.

[10] Commission on International Education., "Educating for Global Competence: America's Passport to the Future", Washington, DC. American Council of Education, 1998.

[11] Did you know. Retrieved on February 25, 2021 from http://www.youtube.com/watch?v=OhuV_rmf5Mg.

[12] Kamenetz, Anya ., (2009) "How Web Savvy Edupunks are Transforming American Higher Education" In Fast Company .com

[13] Duderstadt, James J. (2006). A University for the $21^{\text {st }}$ Century. Ann Arbor MI: University of Michigan Press.

[14] Jones, N. and O'Shea, J. (2004). Challenging hierarchies: the impact of e-learning. Higher Education. 48, 379-395.

[15] Van Damme, D. (2001). Higher education in the age of globalization: The need for a new regulatory framework for recognition, quality assurance and accreditation. Introductory paper for the UNESCO expert meeting. Paris.

[16] Lefrere, P. (2007). Competing higher education futures in a globalized world. European Journal of Higher Education. 42(2), 201-212.

[17] Stromquist, N. P. (2007). Internationalization as a response to globalization: Radical shifts in university environments. Higher Education. 53(1). 81-105.

[18] Pursel, B. K., Zhang, L., Jablokow, K. W., Choi, G. W., and Velegol, D. (2016). Understanding MOOC students: motivations and behaviours indicative of MOOC completion. Journal of Computer Assisted Learning. 32, 202-217.

[19] Ark, T., and Liebtag, E., "Educating for global competence: 6 reasons, 7 competencies, 8 strategies, 9 innovations", Retrieved on March 2, 2021 from https://www.gettingsmart.com/2017/09/educating-for-globalcompetence-6-reasons-7-competencies-8-strategies-9-innovations/.

[20] Ilyas, M., "Engineering Education and Global Competencies", WEEF \& GEDC 2016, Seoul, South Korea, November 2016.

[21] Hunter, B., White, G. P., and Godbey, G. C., "What Does it Mean to be Globally Competent?", Journal of Studies in International Education, 10(3), 2006, pp. 267-285.

[22] Ilyas, M., "Engineering Education and Global Competencies", WEEF \& GEDC 2016, Seoul, South Korea, November 2016. 